\title{
Artigos
}

\section{O uso das tecnologias de informação e comunicação no ensino de língua e suas implicações}

\section{The use of information and communication technology in language teaching and its implications}

\begin{abstract}
Marlete Sandra Diedrich* Patrícia Valério**

Resumo: Refletir acerca do uso das tecnologias digitais na sociedade letrada é também tarefa do professor de língua, em especial, daqueles que trabalham com o ensino mediado por computador. Sendo assim, focalizamos neste artigo a necessidade de aprimoramento das habilidades discursivas dos educandos que vivem experiências de ensino de língua a distância, mais especificamente, de ensino em ambientes virtuais de aprendizagem (AVA). A experiência como professores de língua portuguesa, construída nas interações promovidas em AVA, tem nos apontado a necessidade de preparar o educando para o uso de ferramentas digitais de forma consciente e produtiva, a fim de que ele seja capaz de usufruir desses benefícios enquanto leitor e produtor de textos. Partimos de uma perspectiva funcionalista do objeto língua, segundo a qual falar e escrever bem é, antes de tudo, ser bem-sucedido na interação. Inicialmente, discutimos o conceito de tecnologias da informação e comunicação e sua relação com a prática de letramento; na sequência, focalizamos as habilidades discursivas necessárias para o sujeito interagir de forma produtiva em seu espaço social, virtual ou não, a partir da modalidade escrita; por fim, propomos alguns caminhos na busca do aprimoramento dessas habilidades tendo como recurso as TICs.
\end{abstract}

Palavras-chave: ambiente virtual de aprendizagem; habilidades discursivas; letramento; tecnologias digitais

\begin{abstract}
To reflect about the use of digital technologies in a literate society is also a task to language teachers, particularly among those who work with computer-mediated teaching. Therefore, in this article, we focus on the necessity of improving the students' discursive skills, those who live experiences of language distance learning, especially in virtual learning environment (VLE). The experience as a Portuguese teacher, built on interactions promoted by the VLE, has pointed us to the need of preparing students to a conscious and productive use of digital tools, in order to make them capable to take advantage of the benefits as a reader and a text producer. We start by a functionalist perspective of the object language, whereby speaking and writing well is, above all, succeeding on interactions. First, we discuss the concept of information and communications technology and its relation to literacy practice; after that, we focus on discursive skills required for productive interactions of an individual in his social sphere, virtual or not virtual, from written modality; finally, we propose some ways to improve those skills having the ICTs as a resource.
\end{abstract}

Keywords: virtual learning environment; discursive skills; literacy; digital technology.

\footnotetext{
* Doutoranda do Programa de Pós-Graduação em Letras, da UFRGS. Professora de Língua Portuguesa, Linguística e Estágio Supervisionado da Universidade de Passo Fundo, RS.

** Doutoranda do Programa de Pós-Graduação em Letras, da Unisinos, RS. Professora de Língua Portuguesa e Estágio Supervisionado da Universidade de Passo Fundo, RS. Coordenadora do curso de Letras da Universidade de Passo Fundo.
} 


\section{Considerações Iniciais}

Propomos neste artigo uma discussão acerca da seguinte questão: o ensino de língua mediado por computador exige habilidades linguísticas específicas e diferenciadas daquelas necessárias para o trabalho na modalidade presencial? Para responder a essa questão, voltamo-nos, inicialmente, para nossa experiência como professoras de língua portuguesa em cursos de graduação, uma vez que usamos, em nossas aulas, ambientes virtuais de aprendizagem (AVA). A experiência construída nas interações promovidas em AVA tem nos apontado a necessidade de preparar o educando para o uso de ferramentas digitais de forma consciente e produtiva, a fim de que ele seja capaz de usufruir dos recursos tecnológicos na sua formação enquanto leitor e produtor de textos. Infelizmente, o que temos verificado nos cursos de graduação nos quais atuamos é que muitos educandos chegam ao curso superior com suas habilidades discursivas extremamente limitadas, apesar de ter acesso às tecnologias de informação e comunicação desde cedo.

De posse dessa informação, acreditamos que, de fato, a situação enunciativa vivenciada no ensino de língua mediado por computador requer habilidades discursivas específicas, uma vez que se trata de uma interação que faz uso da modalidade escrita, em grande parte das propostas de aula, mas com características interacionais que visam à criação de um simulacro conversacional, ou seja, há a necessidade de se promover uma aproximação por meio da linguagem escrita, a qual, para atingir seus objetivos, deverá apresentar certas características da interação oral. Com esse posicionamento, buscamos numa perspectiva funcionalista do objeto língua, segundo a qual falar e escrever bem é, antes de tudo, ser bem-sucedido na interação, subsídios para o desenvolvimento de uma proposta de ensino de língua portuguesa que dê conta do aprimoramento das habilidades discursivas explorando as tecnologias digitais disponíveis.

Para dar conta desse desafio, organizamos este artigo da seguinte forma: inicialmente, definimos o que são tecnologias da informação e comunicação; na sequência, refletimos acerca das habilidades discursivas necessárias para o sujeito interagir de forma produtiva em seu espaço social, seja ele virtual ou não, a partir da modalidade escrita; por fim, propomos, tendo em vista nossa experiência em salas de aula virtuais, alguns caminhos na busca do aprimoramento dessas habilidades tendo como recurso as TICs. 


\section{As tecnologias da informação e comunicação}

Referimo-nos aqui às tecnologias de informação e comunicação que dão suporte às atividades realizadas em ambientes digitais de aprendizagem, as quais representam sistemas computacionais disponíveis na Internet. Essas tecnologias permitem integrar linguagens e recursos, promovendo a interação entre pessoas e objetos de conhecimento a partir da apresentação e manipulação de informações de maneira organizada. A elaboração e a sociabilização de produções são atividades centrais no manuseio das TICs em ambientes virtuais de aprendizagem.

\section{Habilidades discursivas}

As produções realizadas em ambientes virtuais de aprendizagem exigem o desenvolvimento das habilidades discursivas de leitura e escrita de textos de diferentes gêneros. O que discutimos aqui, portanto, são as possibilidades de exploração de tais habilidades com o uso dessas tecnologias.

Sabemos, por meio de trabalhos anteriormente publicados, em especial, Primo (2007) e Marcuschi (2004), que a Web 2.0, caracterizada pela sua capacidade de potencializar as formas de publicação, compartilhamento e organização de informações, e de ampliar os espaços interativos, revolucionou as práticas de linguagem e, por decorrência, as de leitura e escrita.

E isso se deve, em especial, à hipertextualidade. Apesar de já existir e marcar textos bem mais antigos que os disponibilizados na internet, foi somente com este advento que a hipertextualidade passou a chamar tanto a nossa atenção e se popularizar. Segundo Lévy (1996), esta característica nos meios digitais "desterritorializa o texto", tornando-o muito mais dinâmico, já que sua organização, seleção e contextualização dependem muito do leitor, inclusive seu início, meio e fim, numa estrutura muitas vezes flexibilizada pelas intenções de busca de quem o lê.

Neste trabalho, focaremos o uso de fóruns no AVA Moodle, como atividade de ensino de Língua Portuguesa. Como se trata de aulas de Leitura e Produção de Textos para graduandos de diferentes cursos de uma universidade, perseguimos nestas aulas o principal objetivo de levar estes graduandos a aperfeiçoar suas habilidades discursivas em situações reais de comunicação. Assim, o fórum disponibilizado na plataforma Moodle surge como um recurso bastante produtivo na busca do objetivo em questão. 
Isso porque, como sabemos, um fórum exige não apenas a postagem de um texto produzido pelo sujeito, mas, principalmente, a capacidade de interagir com os demais participantes desta atividade, o que, certamente, vai exigir a habilidade de leitura crítica, capaz de desencadear um processo interacional.

Para falarmos de interação, assumimos o conceito de Preti (2002, p.45), quando afirma que:

O conceito de interação pode ser entendido em sociedade sob o ponto de vista da reciprocidade do comportamento das pessoas, quando em presença uma das outras, numa escala que vai da cooperação ao conflito. De uma maneira geral, pode-se partir desde uma simples copresença em que dois indivíduos se cruzam na rua e que, mesmo sem se conhecerem, se observam, guardam distância e desviam-se para não se chocarem, o que já demonstra uma ação eonjunta e socialmente planejada, até a interação com um único foco de atenção visual e cognitiva, como a conversação, em que os falantes por um momento se concentram um no outro e se ligam, não só pelos conhecimentos que partilham, mas também por outros fatores socioculturais, expressos na maneira como produzem o seu discurso e conduzem o diálogo.

Para que esta interação verdadeirạmente ocorra no fórum, o graduando em questão precisa, primeiramente, mobilizar seu conhecimento de mundo acerca do assunto proposto; em segundo lugar, necessita entrar em contato com os textos disponibilizados na plataforma Moodle a fim de delimitar sua visão do objeto de estudo e compreender o enfoque a ele dado no contexto em questão; para, finalmente, acessar o fórum e não apenas postar seu texto produzido a partir das implicações anteriores, mas principalmente, compreender o que os demais interactantes estão postando e relacionar com os resultados de suas tarefas anteriores, na busca de uma coerência interna das atividades desenvolvidas, para só depois de todas essas operações cognitivas, produzir seu texto.

E é importante dizermos aqui que não se trata de um texto qualquer, mas um texto com características específicas, ou seja, marcas linguísticas capazes de revelar seu caráter interacional, tanto no que diz respeito aos demais interactantes, como no que diz respeito ao sujeito que se pronuncia e ao próprio objeto de discussão. Acerca desse texto, encontramos em Hilgert (2007, p.73) uma análise que o define bem para os limites de nosso interesse nessa reflexão aqui apresentada:

quem determina o grau de oralidade e de escrituralidade nos textos são as situações de comunicação. Em termos gerais, situações marcadas 
pela proximidade determinariam a oralidade; situações caracterizadas pela distância promoveriam a escrituralidade. À proximidade e à distância está vinculada uma série de fatores que configuram os interlocutores e suas relações interativas, tais como o grau de privacidade, de cumplicidade, de envolvimento emocional, de espontaneidade, de cooperação, de dialogicidade. Essas condições vão ser responsáveis pelo uso ora de uma linguagem mais verbal, ora de uma linguagem mais fortemente impregnada de recursos não verbais. Outras condições vão valorizar mais ou menos os aspectos entonacionais nas formulações linguísticas. Enfim, situações de proximidade e distância vão determinar diferentes formas e estruturas que identificam os mais variados gêneros de textos.

Com essa passagem, o autor aponta os aspectos conceituais do texto falado e do texto escrito, o que nos leva a entender que o texto produzido em situações interativas vivenciadas nos fóruns promovidos nas aulas virtuais caracteriza-se por ser um texto escrito apenas porque se faz uso de recursos gráficos, entretanto, suas características de produção o aproximam do texto falado.

Assim, cremos numa verdadeira interface entre modalidade falada e escrita, em que características de uma acabam por interferir na outra. Por essa razão, o texto produzido na interação em EaD é, do ponto de vista medial, escrito, entretanto, cria um simulacro de fala, uma vez que na narrativa proposta as personagens encontram-se em situação de interação falada, o que, sem dúvida, desencadeia fenômenos linguísticos bastante singulares na constituição do texto.

Infelizmente, o que percebemos em grande parte dos fóruns desenvolvidos em nossas aulas de Leitura e Produção de Textos é a limitação dos sujeitos participantes em relação ao uso de suas habilidades discursivas na produção desse gênero em especial. Ilustramos esta constatação com as seguintes descrições:

1. O sujeito se limita a produzir comentários superficiais, apenas para se marcar no jogo interacional, mas sem garantir a progressão temática. Esta limitação fica visível em expressões como "Muito bem, colega." ou "Concordo com você." Parece-nos que nestas circunstâncias o que encontramos é um sujeito que pretende apenas se marcar no discurso, muito semelhante ao que ocorre nas redes sociais, em que o mais importante, em muitos casos, parece ser dizer “estive aqui". Ousamos caracterizar estas intervenções como sinais fáticos, uma 
espécie de teste do canal de comunicação, mas sem contribuição semântica ou argumentativa significativa.

2. O sujeito se limita a escrever seu ponto de vista, nem sempre embasado ou delimitado pelos textos anteriormente disponibilizados na plataforma Moodle, sem nenhuma referência, explícita ou implícita, ao texto postado pelos demais interactantes. Neste caso, consideramos que não há interação, uma vez que o sujeito produz seu dizer sem levar em conta o dizer do outro, ou seja, parece não ter entendido o que é um fórum e seu objetivo de provocar a troca de ideias, a discussão, a contraposição de argumentos. Vale lembrar aqui que a questão do cumprimento dos prazos estabelecidos para execução desta atividade é fator determinante neste processo. Por se tratar de um fórum, espera-se que o graduando acesse-o várias vezes durante o período em que a atividade se encontra disponível, porque somente assim conseguirá acompanhar devidamente a instauração e incremento da discussão posta, assumindo seu lugar neste meio. Entretanto, o que se verifica, na maioria das vezes, é que muitos graduandos acessam a plataforma quando o prazo para realização já está exíguo, o que, certamente, os impele a uma participação quase isolada dos demais.

Essas duas situações nos remetem ao fato de que o fórum, apesar de ser uma das ferramentas tecnológicas de informação e comunicação, é também um novo gênero textual, com características próprias. Pensar na funcionalidade e intencionalidade de um fórum é, portanto, tarefa dos professores em geral e, principalmente, daqueles que trabalham com a língua, pois é por meio do uso linguístico que o indivíduo vai se constituir sujeito do seu dizer.

Estes fatos nos apontam para a seguinte realidade: viver numa sociedade letrada hoje exige um refinamento no processo de comunicação. Não basta o sujeito estar informado, faz-se necessário que ele produza um novo dizer a partir desta informação, numa rede colaborativa que se forma, no caso aqui focado, no fórum.

Dito isso acerca de nossas percepções na disciplina de Leitura e Produção de Textos Semipresencial no ensino superior, ousamos apresentar algumas reflexões sobre o que, acreditamos, podemos e precisamos desenvolver em nossas aulas no intuito de melhor preparar o sujeito que chega à universidade no que se refere às habilidades 
discursivas necessárias para lidar com as novas tecnologias de forma produtiva, assumindo seu papel de sujeito no processo de ensino-aprendizagem.

\section{Caminhos possíveis}

A habilidade de leitura envolve a capacidade de (re)agir e posicionar-se frente a diferentes textos. Ler, portanto, exige conhecimento prévio a fim de que o sujeito possa, efetivamente, participar da construção dos sentidos na coletividade do ato de linguagem. Por essa razão, o trabalho com a leitura precisa criar oportunidades para a prática de ações significantes desde as primeiras etapas escolares.

Nesse processo, a habilidade de escrever diz respeito ao ato de produzir textos com determinados propósitos para determinados interlocutores em veículos distintos de forma que o sujeito possa inserir-se de modo mais participativo na sociedade. Da mesma forma que a leitura, a escrita envolve codificar letras, sons, imagens, gestos para expressar significados possíveis, participar da construção de sentidos do texto, usando o conhecimento prévio e o repertório de recursos expressivos das linguagens que conhece, selecionar e usar esses recursos em situações específicas de interlocução.

Acreditamos, portanto, ser função das aulas de Língua Portuguesa em geral construir oportunidades em que o sujeito possa interagir no meio em que vive por meio da linguagem, em especial, a escrita, reconhecendo funções sociais para a escrita em sua vida, o que aponta para a verdadeira constituição de autoria. Isso se consegue com o uso das diversas ferramentas de comunicação, destacando, entre elas, as redes sociais e os ambientes virtuais em geral. Entretanto, não se trata apenas de usá-las, mas de refletir acerca deste uso, do como a comunicação se efetiva, de como se obtém sucesso com ela ou não e por quê. Dentre essas ferramentas, certamente, encontram-se as TICs, as quais parecem já fazer parte do cotidiano da educação, mas, na maioria das vezes, sem o devido encaminhamento que se esperaria de um trabalho voltado à educação.

\section{Considerações Finais}

Nosso intuito principal, neste artigo, foi refletir acerca do aprimoramento de habilidades discursivas com o uso das TICs, sem a pretensão, no entanto, de apresentar guias ou fórmulas de ação que possam ditar metodologias para o trabalho com o ensino de língua. Pelo contrário, não temos respostas prontas, pois o questionamento nos impele a pensar e repensar propostas, principalmente, quando se trata de um elemento 
tão novo como as novas tecnologias de informação e comunicação. Nesse contexto, acreditamos ser necessário dizer que a inovação tecnológica permite o uso de diversas tecnologias, e isso, sem dúvida, representa elemento redirecionador das práticas educacionais em geral numa sociedade letrada. Entretanto, consideramos que a grande tecnologia humana presente nas relações sociais é o aparato linguístico, capaz de estabelecer relações entre os interactantes em geral e com os diferentes objetos de estudo focalizados em cada ambiente escolar, seja ele virtual ou presencial. A língua, portanto, vista em sua funcionalidade social, verificada em cada situação comunícativa vivenciada pelos seus usuários, revela-se recurso tecnológico capaz de mudar paradigmas, formar opiniões numa rede conceitual em que os elementos linguísticos assumem sentidos na situação em que são postos em cena no simulacro interacional construídos pelos interactantes, os quais só podem ser assim vistos se assumirem a intencionalidade do seu dizer.

O texto, assim, é concebido como resultado de escolhas linguísticas realizadas com vistas à satisfação de intenções comunicativas por parte do interlocutor. Logo, trabalhar um texto significa trabalhar a gramática que dele emerge. Usamos o termo "gramática" segundo concepção de Neves (2006, p. 16), que considera a existência de motivações externas na gramática, "o que implica o reconhecimento de um componente pragmático para organizar a interação". Somos motivados, assim, à reflexão sobre os motivos que levaram o produtor deste texto a escolher tais construções lexicais, sintáticas, uma vez que elas desencadeiam diferentes efeitos de sentido no interior do texto, os quais vão interferir na situação interlocutiva vivida pelo seu produtor.

No caso do ensino de língua a distância, essa situação interlocutiva assume características específicas que precisam ser levadas em consideração, numa abordagem voltada para a discussão dos fatores situacionais que influenciam a construção linguística, tais como distância física, suscitação de respostas, entre outros. Acreditamos que essa constatação responde nossa pergunta inicial: o ensino de língua mediado por computador exige e explora habilidades linguísticas de cunho interacional, as quais muito se aproximam das habilidades requeridas do sujeito em suas interações cotidianas, em situações de uso efetivo e real da língua. 


\section{Referências}

HILGERT, J. G.. Língua falada e enunciação. Calidoscópio, São Leolpoldo: Unisinos, Vol. 5, n. 2, mai/ago 2007, São Leolpoldo: Unisinos.

LEVY, P.. O que é o virtual. São Paulo: Editora 34,1996.

MARCUSCHI, L.A. Gêneros textuais emergentes no contexto da tecnologia digital. In: MARCUSCHI, L. A., XAVIER, A. C. (Org.). Hipertexto e gêneros digitais. Rio de Janeiro: Lucerna, 2004.

NEVES, M. H. de M.. Texto e gramática. São Paulo, Contexto, 2006.

PRETI, D. (Org.). Interação na fala e na escrita. São Paulo: Humanitas Publicações, 2002.

PRIMO, A. Interação mediada por computador: comunicação, cibercultura, cognição. Porto Alegre: Sulina, 2007.

Artigo recebido em: 11.09.2012

Artigo aprovado em: 18.12.2012 